were completed by a partnership between Botanic Gardens Conservation International, Universiti Brunei Darussalam, Sabah Forestry Department, Universiti of Malaysia Sabah, Forestry Department Sarawak, Bogor Botanic Gardens, The Indonesian Institute of Sciences (LIPI) and Arboretum Sylva Untan (Pontianak, Kalimantan). All these organizations carry out research on and conservation of dipterocarps both in situ and ex situ. This work is showcased in seven case studies in the report.

Only 47 of the 162 endemic species are held in ex situ collections, but 146 species (90\%) occur in protected areas. Priorities for the group are investment in and maintenance and expansion of in situ conservation, particularly for the 15 threatened species that do not occur in either protected areas or ex situ collections.

Dipterocarps are under serious threat in their centre of diversity and a range of conservation actions are needed to protect them. To mobilize and inspire conservation efforts for this group, conservation recommendations are outlined in the report, including details of the Global Conservation Consortium for Dipterocarps, established in early 2021, which aims to develop a network of dipterocarp experts to coordinate action and share knowledge and expertise.

MEGAN BARSTOW (๑ orcid.org/0000-0001-9835-2933, megan.barstow@bgci.org) Botanic Gardens Conservation International, Richmond, UK, and IUCN Species Survival Commission Global Tree Specialist Group. DAVID BARTHOLOMEW (ㅇ 0000-0002-8123-1817) School of Geography, University of Exeter, Exeter, UK

This is an Open Access article, distributed under the terms of the Creative Commons Attribution licence CC BY 4.0.

\section{Nubian flapshell turtle found in northern Uganda}

The Nubian flapshell turtle Cyclanorbis elegans is categorized as Critically Endangered on the IUCN Red List (2021) and is one of the five most threatened chelonians. This species, which was previously presumed extinct, was rediscovered in 2017 along the White Nile in South Sudan, where for the last 4 years we have been studying its distribution, population size and conservation status, and potential threats (Luiselli et al., 2021, Oryx, 55, 490).

In August-September 2021, funded by the Turtle Survival Alliance, USA, we focused our surveys on the border region between South Sudan and Uganda, where the species has never previously been recorded. This area is characterized by gallery forests along the White Nile river course, and the marshlands of the Onyama River and of the Paanzalla, Difule and Laropi areas. This was once the last sanctuary in this region for the white rhinoceros Ceratotherium simum, which was extirpated in the late 1980 os during the civil unrest that afflicted Uganda and South Sudan.

During our surveys, by five surveyors in 600 personhours over 12 days, we observed one live Nubian flapshell

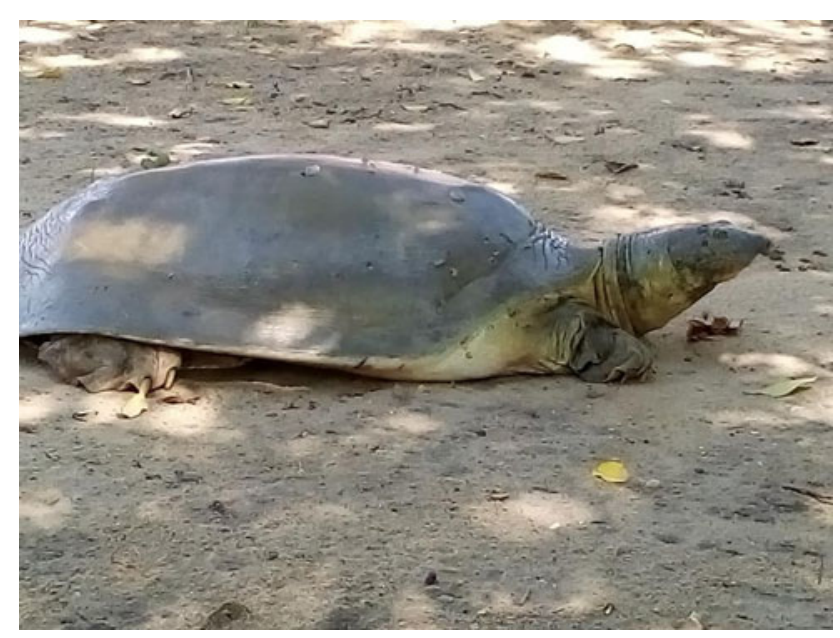

A Nubian flapshell turtle Cyclanorbis elegans found in northern Uganda. Carapace length was $73.4 \mathrm{~cm}$. Photo: Gift Simon Demaya.

turtle and the shells of three additional individuals, in a remote area of northern Uganda bordering South Sudan (the exact location is not provided here, for the security of the species). Nothing is as yet known about the population size and viability of this population, although we presume that it may be overexploited, as the turtle is captured by local fishermen both for subsistence and for sale. As the area is remote and not yet severely altered by development, habitat loss in this region does not appear to be a threat to the species.

LUCA LUISELLI (ㅇorcid.org/0000-0001-6878-2916, l.luiselli@ ideccngo.org) Institute for Development, Ecology, Conservation and Cooperation, Rome, Italy. GIFT SIMON DEMAYA,

John Sebit Benansio, Thomas Francis Lado and Salah Jubarah Department of Wildlife Science, University of Juba, Juba, South Sudan

This is an Open Access article, distributed under the terms of the Creative Commons Attribution licence CC BY NC 4.0.

\section{Human-carnivore conflict management in the central High Atlas mountains of Morocco}

The central High Atlas mountains of Morocco encompass an area of $10,502 \mathrm{~km}^{2}$ and have a rich biological diversity. The last observations of the serval Leptailurus serval, leopard Panthera pardus and Barbary lion Panthera leo in Morocco were in these mountains. This area is still home to eight carnivore species (golden jackal Canis aureus, African wolf Canis lupus lupaster, red fox Vulpes vulpes, wild cat Felis silvestris, striped hyaena Hyaena hyaena, Eurasian otter Lutra lutra, common genet Genetta genetta and least weasel Mustela nivalis), two of which are categorized as Near Threatened on the IUCN Red List.

On 5 May 2021, the M'goun Geopark Association and the Moroccan Association of Life and Earth Sciences Teachers, in collaboration with the Sultan Moulay Slimane, Cadi Ayyad and Hassan II universities, organized a workshop to examine the 